\title{
Pediatric Mucormycosis and COVID-19
}

\author{
Shikha Yadav \\ The Journal of Contemporary Dental Practice (2021): 10.5005/jp-journals-10024-3151
}

Dear Editor,

As of May 19, 2021, due to the increase in reported mucormycosis cases in COVID-19 patients, mucormycosis has been declared as a notifiable disease under Epidemic Disease Act 1897 by the Government of India with the prevalence being 140 per million population. The first case of mucormycosis in a pediatric COVID-19 positive child has been reported in Ahmedabad ${ }^{1}$ and we should prepare ourselves with the probability of more pediatric cases being reported in the near future.

Mucormycosis is an uncommon but fatal fungal infection that usually affects patients with altered immunity. Mucormycosis is an angioinvasive disease caused by mold fungi of the genus Rhizopus, Mucor, Rhizomucor, Cunninghamella, and Absidia of Order-Mucorales, Class-Zygomycetes. It is generally subdivided into five clinical entities: (1) rhinocerebral, (2) pulmonary, (3) gastrointestinal, (4) cutaneous, and (5) disseminated diseases. Rhinocerebral disease is the most common form of mucormycosis in adults and children. ${ }^{2}$

Rise in mucormycosis may be associated with the unwarranted permutation and combination between diabetes, injudicious use of steroids, and COVID-19 infection. ${ }^{3}$

Mucormycosis represents the third most common invasive fungal infection in children. Pediatric patients are all so unique in many ways and the most challenging part for any clinician is the inability of the children to verbally express their complaints. In this scenario, we dental surgeons, pediatric dental surgeons, and maxillofacial surgeons should be extra cautious while examining and evaluating pediatric cases with a chief complaint of loose teeth, swollen cheeks and infraorbital regions, eye pain, palatal discoloration, and nonhealing ulcers, especially those who have been tested COVID-19 positive and have been provided prolonged treatment. It would be advisable that loosening of deciduous teeth should not be confused with that secondary to mucormycosis infection.

With patient management at times taking place via telemedicine, it is paramount that past history is obtained in-depth and at any suspicion of mucormycosis infection adequate measures should be taken immediately. In the case of pediatric patients who are immunocompromised, it would be astute to send them for further evaluation if they are showing any signs and symptoms of mucormycosis infection even if they have not been diagnosed or admitted for COVID-19 treatment. When the diagnosis is suspected, it requires an urgent evaluation of clinical samples. Mucormycosis infection requires aggressive surgical intervention to prevent contiguous spread and dissemination and medical management with antifungal drugs by a multidisciplinary team which may constitute pediatricians, pediatric and maxillofacial surgeons, pediatric dentists, and prosthodontists for rehabilitation. ${ }^{4,5}$
Department of Dentistry, All India Institute of Medical Sciences, Mangalagiri, Andhra Pradesh, India

Corresponding Author: Shikha Yadav, Department of Dentistry, All India Institute of Medical Sciences, Mangalagiri, Andhra Pradesh, India, Phone: +91 8872792010, e-mail: drshikhayadav@gmail.com

How to cite this article: Yadav S. Pediatric Mucormycosis and COVID-19. J Contemp Dent Pract 2021;22(8):855.

Source of support: Nil

Conflict of interest: None

Treatment of mucormycosis is a race against time as its case fatality rate is high, especially for neonates. ${ }^{5}$ The sooner the diagnosis is made it not only points toward a better prognosis but there is a better probability of salvaging more hard and soft tissues. This is not only paramount in relation to the fact that growth is incomplete in children and the more we are able to salvage will give the better chance for all the bones to grow properly and the aesthetic part can never be discounted in children. Aesthetics is very crucial for children as well and this may prevent or lessen the strain on their mental health especially when they are school-going and may face bullying at school and playgrounds. An early diagnosis is the first step and the most important step in that direction.

\section{OrCID}

Shikha Yadav ํㅏㄴ https://orcid.org/0000-0002-7721-8011

\section{References}

1. Gujarat sees 54 COVID deaths; 15 -year-old boy becomes Ahmedabad's first case of pediatric mucormycosis. Available from: https://www. newindianexpress.com/nation/2021/may/22/gujarat-sees-54coviddeaths15-year-old-boy-becomes-ahmedabads-first-caseofpediatric-mucormycosis-2306249.html [Accessed on May 24, 2021].

2. Otto WR, Pahud BA, Yin DE. Pediatric mucormycosis: a 10-year systematic review of reported cases and review of the literature. J Pediatric Infect Dis Soc 2019;8(4):342-350. DOI: 10.1093/jpids/piz007. PMID: 31181136.

3. Singh AK, Singh R, Joshi SR, et al. Mucormycosis in COVID-19: a systematic review of cases reported worldwide and in India. Diabetes Metab Syndr 2021;15(4):102146. DOI: 10.1016/j.dsx.2021.05.019.

4. Kalaskar RR, Kalaskar AR, Ganvir S. Oral mucormycosis in an 18-month-old child: a rare case report with a literature review. J Korean Assoc Oral Maxillofac Surg 2016;42(2):105-110. DOI: 10.5125/ jkaoms.2016.42.2.105.

5. Francis JR, Villanueva $P$, Bryant $P$, et al. Mucormycosis in children: review and recommendations for management. J Pediatric Infect Dis Soc 2018;7(2):159-164. DOI: 10.1093/jpids/pix107. PMID: 29294067.

(o) The Author(s). 2021 Open Access This article is distributed under the terms of the Creative Commons Attribution 4.0 International License (https://creativecommons. org/licenses/by-nc/4.0/), which permits unrestricted use, distribution, and non-commercial reproduction in any medium, provided you give appropriate credit to the original author(s) and the source, provide a link to the Creative Commons license, and indicate if changes were made. The Creative Commons Public Domain Dedication waiver (http://creativecommons.org/publicdomain/zero/1.0/) applies to the data made available in this article, unless otherwise stated. 